\title{
EL COMERCIO MARÍTIMO DE ALICANTE HACIA VALENCIA EN EL SEGUNDO CUARTO DEL SEISCIENTOS (1626-1650)
}

\author{
ROBERTO BLANES ANDRÉS
}

En memoria de: Pepe Martí Llopis

El presente estudio tiene como objetivo la aproximación al comercio marítimo que se estableció desde la ciudad de Alicante hacia la de Valencia a lo largo del segundo cuarto del Seiscientos. Para ello hemos aprovechado las fuentes documentales de la serie Peatge de Mar, preservada en el Archivo del Reino de Valencia, perteneciente a la sección del Maestre Racional. Dicho catálogo abarca un extenso período de la época foral moderna, con fechas límites en 1491 (signatura 10915) y 1707 (signatura 11060), aunque con las lógicas lagunas intermedias, parciales en unos casos, de años completos en otros ${ }^{1}$.

La finalidad de estas fuentes era dejar evidencia cotidiana de los navíos que atracaban en la playa del Grao de Valencia, pormenorizándose, en un prólogo inicial, la fecha (en letra y número), el tipo de navío, el nombre del patrón (si era una nave modesta) o del capitán (si dirigía un buque de gran calado). En algunas ocasiones se especificaba el lugar de procedencia de estos personajes; proseguía el puerto de donde había partido, escalas efectuadas en la trayecto hacia Valencia y la cantidad satisfecha en función de la tipología del cargamento. A continuación el funcionario encargado inscribía el cargamento, detallando de volumen y naturaleza del mismo, los agentes con él relacionados, bien en calidad de remitentes como de destinatarios, así como de las cantidades satisfechas por los distintos tipos impositivos con que eran gravados los diferentes artículos. La firmeza argumental se flexibiliza y engrandece, aunque de forma esporádica, con los diversos acontecimientos surgidos en la travesía: presencia en algún punto de la ruta de naves berberiscas, contratiempos padecidos en la opera-

\footnotetext{
1. SAlvador Esteban, E., «El tráfico marítimo Barcelona-Valencia durante los siglos XVI y XVII. Su significado en el conjunto del comercio importador valenciano» Pedralbes, Revista d'Història Moderna, no 10, Barcelona, 1990, p. 19.
} 
ción de atraque, inclemencias climáticas, dársenas afectadas por enfermedades infectocontagiosas, la captura de naves hostiles, paridades de pesos de diferentes espacios geográficos en correspondencia con los dominantes en Valencia o el próximo destino de los buques.

Las carencias que muestran las partidas documentales, así como el estado de conservación de algunos volúmenes de la serie ${ }^{2}$, ha limitado nuestro análisis a la fiscalización de 13 años, intercalados entre 1626 y 1650, y dispuestos de forma desigual. A pesar de ello, opinamos que son suficientemente significativos como para proporcionarnos un enfoque lo bastante aproximado de lo que debió de ser la trayectoria exportadora alicantina a Valencia en el periodo temporal que vamos a analizar.

La riqueza de contenidos (que se me permitirá calificar de extraordinarios) y el carácter excepcional dentro del ámbito valenciano e incluso europeo ha sido puesto de

2. Archivo del Reino de Valencia (A. R. V.)

\begin{tabular}{|c|c|c|c|c|}
\hline \multicolumn{5}{|c|}{ SECCION DEL MAESTRE RACIONAL } \\
\hline \multicolumn{5}{|c|}{ Serie Peatge de Mar } \\
\hline Año & Período temporal & $\mathbf{N}^{\circ}$ Serie & Legajo & $\mathbf{N}^{0}$ Folios \\
\hline 1626 & Del 8/Enero al 30/Mayo. & 10975 & 552 & Del 181-281 \\
\hline & Del 1/Junio al 31/Diciembre. & 10976 & 552 & Del 22-185 \\
\hline 1627 & Del 1/Enero al 31/Mayo. & 10976 & 552 & Del 186-307 \\
\hline & Del 3/Junio al 31/Diciembre. & 10977 & 553 & Del 2-302 \\
\hline & Del 3/Junio al 27/Diciembre. & 10978 & 553 & Del 1-314 \\
\hline 1628 & \multicolumn{4}{|c|}{$\begin{array}{c}\text { Año incompleto. Sólo se puede consultar los dos primeros meses del año y de } \\
1 \text { de Junio al } 31 \text { de Diciembre. }\end{array}$} \\
\hline 1629 & Del 1/Enero al 31/Mayo. & 10980 & 553 & Del 168-274 \\
\hline & Del 1/Junio al 31/Diciembre. & 10891 & 554 & Del 1-292 \\
\hline 1630 & \multicolumn{4}{|c|}{ Sólo se pueden consultar los 18 primeros días del mes de enero. } \\
\hline 1631 & \multicolumn{4}{|c|}{ Los manuscritos sólo nos informan de la segunda mitad del año } \\
\hline 1632 & \multicolumn{4}{|c|}{ Los datos se concentran en los cinco primeros meses del año } \\
\hline 1633 & \multicolumn{4}{|c|}{ La información se circunscribe a los últimos seis meses del año } \\
\hline 1634 & Del 1/Enero al 11/Diciembre. & 10985 & 555 & Del 1-179 \\
\hline 1635 & Del 3/Enero al 31/Diciembre. & 10986 & 555 & Del 3/146 \\
\hline 1636 & Del 5/Enero al 14/Diciembre. & 10987 & 555 & Del 2-182 \\
\hline & Del 8/Enero al 2/Mayo.. & 10988 & 555 & Del 2-47 \\
\hline 1637 & Del 3/Enero al 11/Diciembre. & 10989 & 555 & Del 2-198 \\
\hline & De 2/Agosto al 27/Diciembre & 10990 & 555 & Del 112-161 \\
\hline 1638 & Del 1/Enero al 31/Diciembre. & 10991 & 555 & Del 2-179 \\
\hline & Del 3/Enero al 1/Marzo.. & 10992 & 555 & Del 2-24 \\
\hline 1639 & \multicolumn{4}{|c|}{ Solamente se pueden consultar los seis primeros meses del año } \\
\hline 1640 & \multicolumn{4}{|c|}{$\begin{array}{c}\text { EI volumen correspondiente al presente año, no se puede consultar por lo } \\
\text { deteriorado que se encuentra. }\end{array}$} \\
\hline 1641 & Del 1/Enero al 31/Diciembre. & 11015 & 562 & Del i2?-97 \\
\hline 1642 & Del 4/Enero al 31/Diciembre. & 11016 & 562 & Del 2-119 \\
\hline 1643 & \multicolumn{4}{|c|}{ Se puede consultar del 2 de Enero al 2 de Junio } \\
\hline 1644 & \multicolumn{4}{|c|}{ No aparece en el catálogo del A. R. V. } \\
\hline 1645 & Del 1/Enero al 29/Diciembre & 11017 & 562 & Del 22-258 \\
\hline 1646 & \multicolumn{4}{|c|}{$\begin{array}{l}\text { Sólo se puede consultar del } 6 \text { al } 9 \text { de Enero y del } 28 \text { de Noviembre al } 3 \text { de } \\
\text { Diciembre. }\end{array}$} \\
\hline 1647 & \multicolumn{4}{|c|}{ No aparece en el catálogo del A. R. V. } \\
\hline 1648 & \multicolumn{4}{|c|}{ No aparece en el catálogo del A. R. V. } \\
\hline 1649 & Del 4/enero al 31/Diciembre. & 11019 & 562 & Del 2-215 \\
\hline 1650 & Del 1/Enero al 31/Diciembre. & 11020 & 563 & Del 22-246 \\
\hline
\end{tabular}


manifiesto por medio de cuatro tesis doctorales publicadas ${ }^{3}$, un amplio número de tesis de licenciatura inéditas y diversos artículos y comunicaciones a congresos certifican su trascendencia.

La primera parte de este sencillo inventario nos proporciona asuntos de sumo interés relacionados con la cantidad total de embarcaciones, sus fluctuaciones anuales, su género, así como los patrones que los comandaban y los puertos que visitaron, en su trayectoria, antes de llegar al nuestro.

En cuanto al número de embarcaciones de procedencia alicantina que fondearon a la playa del Grao de Valencia en el espacio temporal que estamos analizando, podemos señalar que alcanza la suma total de 415 buques, lo que supone un promedio anual que supera los 31 unidades (exactamente 31,9), con oscilaciones que van desde aquellos años en que se asientan 11 y 13 recepciones $^{4}$, hasta los 47 del año 1650.

Ahora bien, para comprender la verdadera magnitud del tráfico portuario de Alicante hacia Valencia, conviene establecer la relación entre este comercio particular con el general que afecta al Grao de Valencia en el mismo período. A lo largo de nuestra investigación se contabilizó un total de 6493 embarcaciones, con una media que no supera las 500 anuales.

Así pues, la primera comparación se establece entre las 415 naves llegadas desde Alicante en este período con el mencionado total de 6493 barcos, lo que supone un 6,4 por 100 del total. Si se opta por el montante anual, el porcentaje es similar, ya que de Alicante llegó un promedio anual de 31 naves y, en general, llegaron unas 500 embarcaciones cada año al puerto de Valencia.

Estos resultados varían sensiblemente si la comparación la realizamos exclusivamente en el ámbito del litoral meridional del Reino de Valencia, un área sembrada de puertos, cuya actividad comercial jugó un papel destacado en el abastecimiento de la ciudad del Turia; así lo atestiguan las 2076 naves oriundas de esta zona (representando el $31,9 \%$ del computo total) procedentes de 24 puertos; Alicante ocupa el segundo lugar por detrás de Denia con 436 y un $21 \%$ del total de unidades procedentes de esta superficie; seguido de lejos por Jávea con 267 (12,8\%), Calpe con 259 (12,5\%), Villajoyosa con $165(7,9 \%)$, Altea con $115(5,5 \%)$ y la Mata con $101(4,8 \%)$; el resto de dársenas no supera en ningún momento el centenar. El fondeadero de Alicante junto con la nómina de puertos mencionados anteriormente, tienen un comportamiento expedidor diferente al del resto de muelles situados entre Valencia y la punta de la Torre de la Horadada. A mayor abundamiento, Alicante mantiene mayor similitud exportadora con Denia, Jávea y Calpe, ya que estas villas quedaron excluidas del paréntesis comercial que sufrió el resto de puertos de aquella zona, en los años 1634, 1635 y 1641, donde la

\footnotetext{
3. Las citaremos por orden cronológico: CASTILlo PinTADO, A., Tráfico marítimo de importación en Valencia a comienzos del siglo XVII, Madrid, 1967; SALVADOR ESTEBAN, E., La economía valenciana en el siglo XVI (Comercio de importación), Valencia, 1973; GUIRAL-HADZIIOsSIF, J., Valencia puerto mediterráneo de importación (1410-1525), Valencia, 1989 y BLANES ANDRÉS, R., El puerto de Valencia: encrucijada de rutas, productos y mercaderes, Biblioteca Valenciana, Valencia, 2003.
}

4. Años 1642 y 1638 respectivamente. 
tónica general fue la ausencia, en la playa del Grao, de buques oriundos de esta área. Dentro del grupo de los cuatro puertos mencionados, Alicante es el único que no sufre la crisis tan aguda que afligió al resto de dársenas, experimentando un comportamiento diferente al aumentar, en los años críticos, el número de embarcaciones. Afirmación que podemos observar en el cuadro realizado a tal efecto.

\begin{tabular}{|c|c|c|c|c|c|c|c|c|c|c|c|c|c|c|}
\hline & 1626 & 1627 & 1629 & 1634 & 1635 & 1636 & 1637 & 1638 & 1641 & 1642 & 1645 & 1649 & 1650 & TOTAL \\
\hline Denia & 35 & 45 & 40 & 16 & 7 & 48 & 49 & 26 & 13 & 41 & 42 & 46 & 28 & 436 \\
\hline Jávea & 21 & 21 & 19 & 3 & 1 & 43 & 36 & 20 & 3 & 16 & 18 & 51 & 15 & 267 \\
\hline Calpe & 10 & 33 & 15 & & 1 & 28 & 19 & 36 & 3 & 38 & 19 & 27 & 29 & 259 \\
\hline Altea & 7 & 7 & 19 & & & 15 & 7 & 2 & & 8 & 12 & 19 & 19 & 115 \\
\hline Villajoyosa & 12 & 11 & 30 & & & 8 & 14 & 3 & 1 & 13 & 27 & 24 & 22 & 165 \\
\hline Alicante & 39 & 26 & 29 & 38 & 41 & 36 & 31 & 13 & 21 & 11 & 46 & 37 & 47 & 415 \\
\hline La Mata & 1 & 4 & 3 & & & 4 & 7 & 13 & & 6 & 20 & 16 & 27 & 101 \\
\hline
\end{tabular}

Otra consecuencia significativa que se desprende del análisis de este cuadro es el comportamiento exportador de la capital alicantina durante el cuatrienio 1638-1642. En efecto, durante este período, las embarcaciones de Alicante pierden presencia en Valencia, en beneficio de las procedentes de sus competidoras en aquella costa, Denia, Jávea y Calpe. Asimismo, cabe resaltar que la diferencia que se observa entre estos puertos y el de Alicante en relación con Valencia es máxima en el último de los años anotados.

Entre las causas que dieron lugar a este paréntesis mercantil no deberían desdeñarse los acontecimientos políticos del momento que convulsionaron el reinado de Felipe IV, tales como el inicio de la guerra hispano-francesa de 1635 o la revolución catalana de $1640^{5}$. Ahora bien, aquello que se yergue como una realidad objetiva es que Alicante supo superar los obstáculos que atenazaban al conjunto, ganándose la confianza de mercaderes y comerciantes, manteniendo un dinamismo marítimo-exportador, en especial en los años de crisis manifiesta, muy superior al resto.

La distribución anual de las embarcaciones alicantinas que fondearon en nuestras aguas costeras con destino a la metrópoli valenciana las hemos agrupado en la siguiente tabla y gráfica:

5. Recordemos que el 7 de mayo de 1642, [...], el marqués de Leganés recibe en Valencia las primeras noticias de la existencia de una poderosa armada francesa de aproximadamente 25 navios (dirigida por el arzobispo de Burdeos) que se encuentra en algún punto de las costas catalanas. [...] Escuadra que se enfrento en 14 de mayo de 1642 en aguas de Peñíscola a la armada española de Dunquerque, comandada por los almirantes Joos Petersen y Salvador Rodríguez, semanas más tarde bombardeará Vinaroz; el 9 de junio de 1945 quemará varias embarcaciones, cargados de grano, en la playa del Grao de Valencia, cañoneando el baluarte situado en dicho punto. Antes que se produzca el enfrentamiento naval en la costa de Peñíscola otra flota francesa de 36 navíos se encuentra en las inmediaciones de Alicante, creando más zozobra entre los estrategas españoles. Sin duda la presencia de las flotas francesas en la costa valenciana redujo considerablemente las exportaciones alicantinas hacia Valencia. HERNÁNDEZ RUANO, J., «David contra Goliat: La batalla naval de Peñíscola en formación de Hilera de frente (14 de mayo de 1642)», IX Jornades d'Estudi del Maestrat, Peñíscola,octubre 2004, Boletín n ${ }^{\circ}$ 72, Julio-Diciembre de 2004, pp. 45-54. 


\begin{tabular}{|l|c|c|c|c|c|c|c|c|c|c|c|c|c|c|}
\hline Años & $\mathbf{1 6 2 6}$ & $\mathbf{1 6 2 7}$ & $\mathbf{1 6 2 9}$ & $\mathbf{1 6 3 4}$ & $\mathbf{1 6 3 5}$ & $\mathbf{1 6 3 6}$ & $\mathbf{1 6 3 7}$ & $\mathbf{1 6 3 8}$ & $\mathbf{1 6 4 1}$ & $\mathbf{1 6 4 2}$ & $\mathbf{1 6 4 5}$ & $\mathbf{1 6 4 9}$ & $\mathbf{1 6 5 0}$ & Total \\
\hline Embarcaciones & 39 & 26 & 29 & 38 & 43 & 36 & 31 & 13 & 21 & 11 & 45 & 37 & 47 & 415 \\
\hline Porcentajes & 9,3 & 6,2 & 7 & 9,1 & 10,3 & 8,7 & 7,5 & 3,2 & 5 & 2,7 & 10,8 & 8,9 & 11,3 & \\
\cline { 1 - 10 }
\end{tabular}

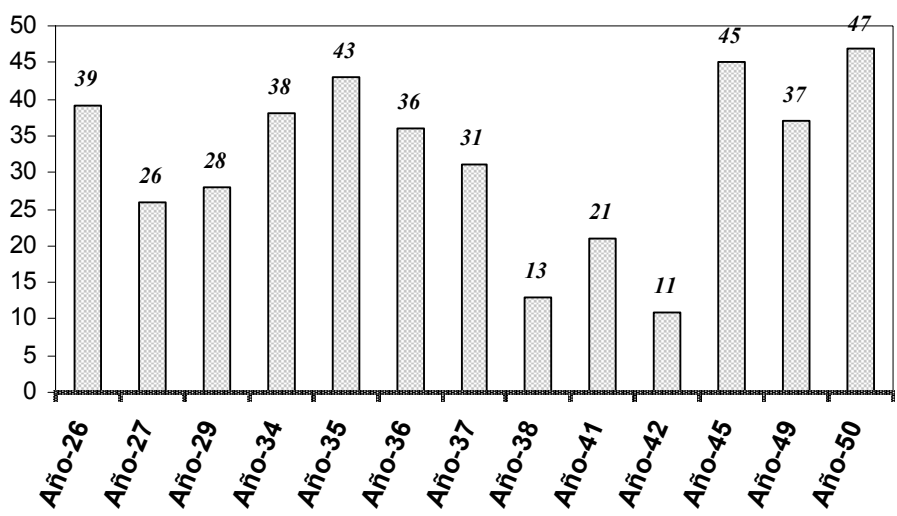

Aunque el perfil detallado, es lo suficiente explícito, no podemos sustraernos a realizar algún comentario; al examinarlo detenidamente la primera información que se nos facilita es la existencia de cinco fases diferenciadas; así tres de ellas superan con claridad la media anual, si bien mantiene sus propias peculiaridades; las dos restantes marcan el periodo más bajo, dibujando dos cubetas distintas entre si. El inicio de este periodo arranca con una etapa alcista (1626) donde se supera con creces la media anual $(+8)$, logrando las 39 unidades (con el 9,3\% del total). Por el contrario los años 1627 y 1629 se caracterizarán por un descenso suave $(5$ y 3 puntos por debajo del índice regulador); dando paso a una nuevo espacio temporal comprendido entre 1634 y 1637 , que se significará por un segundo ascenso en el número de embarcaciones, destacando 1635 por ser el año donde se alcanza la máxima presencia de naves alicantinas (43 unidades) en el puerto playa de Valencia. Ciclo al que le seguirá la etapa más modesta en las exportaciones en términos globales, 1638-1642, destacando el último año de esta fase por alcanzarse el extremo más pobre de todo el lapso temporal que estamos abordando, con 11 buques y un porcentaje que no logra el 3\% del total. Cerraremos este análisis con los efectos obtenidos en los años 1645, 1649 y 1650, donde se obtienen los resultados más espectaculares, al superar al resto de períodos (exceptuando el año 1649) con los exponentes más elevados, al conseguirse 45 y 47 unidades en los extremos temporales de esta etapa y sobrepasando la media anual en 14 y 16 navíos respectivamente, lo que porcentualmente se traduce en un 11 y un $11,3 \%$ del resultado global.

Hasta aquí hemos trabajado exclusivamente con un valor tan arriesgado como el número de embarcaciones. Ahora bien, este antecedente conseguirá su auténtica dimensión cuando hayamos sondeado el cargamento que cada unidad descargó en la playa valenciana. Pero en tanto no poseamos dicha información, un sucinto acerca- 
miento a la temática que estamos abordando nos la puede facilitar las características de los cargueros.

Por lo que concierne al prototipo de buques, nueve son las variantes registradas como se puede observar en el cuadro que adjuntamos.

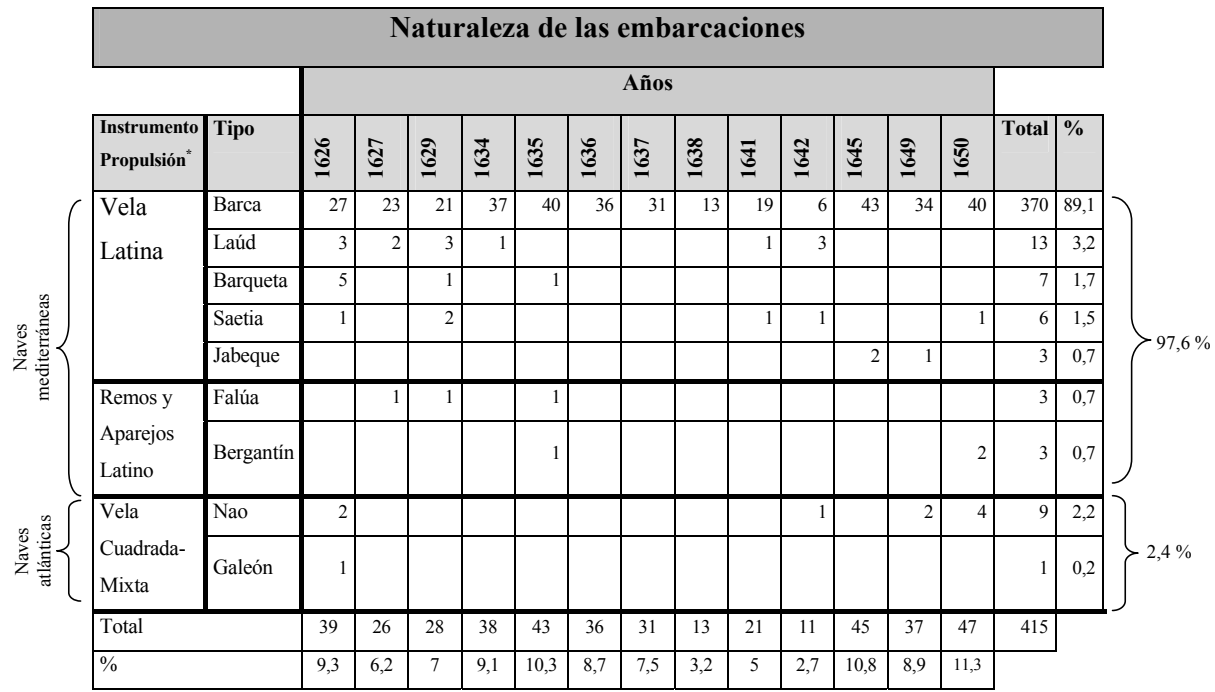

* La división tipología de las embarcaciones está basada en la clasificación adoptada a principios del siglo XVII por el italiano Pantero Pantera (capitán de las galeras pontificias). La base diferenciadora se establece a partir de los diferentes métodos de propulsión utilizados en los buques. De acuerda con ella se pueden distinguir tres grupos: el primero, de velas triangulares o latinas; el segundo, utiliza el remo fundamentalmente, $y$, la vela, triangular como subsidiaria de este y el tercero está formado por aquellas naves que emplean la vela cuadrada y triangular al mismo tiempo.

De los modelos reseñados sobresalen los de raigambre mediterránea, es decir, los que utilizan la vela latina o triangular como técnica de desplazamiento o bien los remos con el anexo del aparejo triangular. De los primeros, la barca con 370 unidades (el $89,1 \%$ del total), aglutina más de las tres cuartas partes de las llegadas. La media anual de este tipo de embarcación se cifra en el 28,4\%; el nivel mínimo de barcas se alcanza en 1641 con 19,1638 con 13 y 1642 con 6 y, el mayor número de barcas se obtiene en 1635 y 1645 con 43 y 45 respectivamente y 1650 con 47 . Ambos extremos coinciden con los espacios temporales más débiles y más fluidos en las relaciones marítimas entre las dos ciudades valencianas. A la barca le sigue, a considerable distancia, el laúd con 13 navíos (3,2\%). Este tipo de nave se mantuvo muy activo en la década de los veinte, desapareciendo en los treinta para reaparecer, puntualmente, en los primeros años de los cuarenta. La barqueta, la hermana menor de la barca, se adjudica el tercer lugar con 7 buques $(1,7 \%)$. El resto de prototipos, de la más añeja tradición mediterránea que les secundan son: la saetía (con el $1,5 \%)$ y el jabeque $(0,7 \%)$. 
El segundo bloque de ascendencia mediterráneo tiene una representación muy pobre al compararlo con el anterior, un balance que no sólo lo podemos detectar al cuantificar el número de embarcaciones, sino en los diferencia de prototipos; sólo dos modelos pertenecientes a esta familia aparecen en las fuentes, la falúa y el bergantín, que se reparten, por igual, los 6 navíos que fondearon en nuestra aguas, alcanzando ambos dos el $0,7 \%$ del total.

Los grandes buques que ondean el velamen cuadrado o mixto, unido a la navegación atlántica, intervienen escasamente en esta corriente de tráfico; estando representados en diez ocasiones, destacando, de entre todos, la nao, modelo asentado en los manuscritos en 9 ocasiones lo que supone el 2,2\% del total. Después, sólo encontramos el galeón, representado con una sola nave (el 0,2\%).

Como se deduce de estos resultados, la proporción numérica de embarcaciones de origen mediterráneo es aplastante (con un 97,6\%) respecto a las de esencia típicamente atlántica $(2,4 \%)$; imponiéndose, en las importaciones hacia Valencia los mercantes de tonelaje reducido.

El predominio de los navíos de raigambre mediterránea sobre los oceánicos y la soberanía de las de mediano y pequeño fondo sobre las de gran tonelaje, nos lleva a apuntar que dominó la navegación de cabotaje, aunque las fuentes se manifiestan insuficientemente reveladoras en relación a este tema. No obstante, la cercanía geográfíca entre Alicante y Valencia debió beneficiar los recorridos directos, como nos lo demuestra el hecho de que de los 415 buques registrados en la parrilla, sólo figuren $73,(17,6 \%)$ con escalas intermedias y de ellos \pm 20 con escala única. Los puertos preferidos, por los patrones, para realizar alguna parada lo lidera Denia con 50 visitas $(68,5 \%)$, le siguen a mucha distancia los puertos de La Mata (con 9 paradas), Jávea (con 5), Villajoyosa (con 4) y un grupo de dársenas que reciben ocasionalmente a las embarcaciones alicantinas como son: Calpe, Morvedre, Cartagena y Plymonth. Por último no podemos dejar de señalar las ocasiones que Alicante juega el papel de escala ${ }^{6}$ de embarcaciones procedentes de otros espacios y que tienen como meta Valencia. La procedencia de estas naves se sitúa en dos espacios diferentes el Mar Interior y el Océano Atlántico, dando lugar a unas rutas estructuradas y dinámicas, al reunir en su desarrollo geográfico, algunos de los puertos más significativos del comercio mediterráneo-atlántico de los siglos XVI y XVII ${ }^{7}$. Los navíos oceánicos zarparon de diferentes espacios geográficos diseminados por la costa occidental europea $y$, en ocasiones puntuales, tendremos que atravesar el Atlántico para encontrar el origen del puerto asentado en los legajos. Iniciaremos este recorrido buscando las dársenas más septentrionales del continente Europeo.

El primero que encontraremos es el topónimo genérico de Noruega (no se especifica ningún lugar geográfico determinado). El puerto más meridional que hallamos a

\footnotetext{
6. Gracias a la minuciosidad de los escribanos que fiscalizaron los productos desembarcados en la playapuerto del Grao, podemos diferenciar los productos procedentes de Alicante, de los artículos transportados desde el puerto de partida o de los adquiridos en la travesía.

7. Del listado de puertos que hemos arrancado de las fuentes, nos ha sido imposible identificar el lugar exacto de los siguientes: Artimu, Sarra y Famelo o Samelo.
} 
continuación es Hamburgo (de donde zarparon dos naves). Del archipiélago británico llegaron 27 buques, de los cuales 4 proceden de Plymonth, el único puerto que se puntualiza; del resto solo se anota que proceden de Inglaterra o Irlanda. El recorrido establecido nos llevará hasta las costas lusitanas, de donde hemos podido rescatar las dársenas de Faro (con 8 unidades), Lagos (con 6), Lisboa (con 4), y Setúbal (con 1). Cerrando este periplo los puertos de la Castilla Atlántica: Cádiz (4 navíos), Sevilla (2) y el Puerto de Santa María y Conil con una. Por último tenemos que destacar las 7 embarcaciones transoceánicas oriundas de Terranova.

El Mediterráneo occidental acogerá el resto de puertos de donde partieron navíos que realizaron alguna visita al puerto alicantino antes de llegar a Valencia; destacando, de entre todos, las dársenas situadas en la Castilla Mediterránea: Cartagena, Motril, Málaga, Almería, las islas Chafarinas y Mazarrón. El norte de África estará representado por 13 embarcaciones procedentes de Orán y Tetuán. La península italiana aportará 4 embarcaciones ( 2 de Liorna y una de Nápoles y Barletta respectivamente). Del área franco-catalana-rosellonesa hemos rescatado 3 barcas (naturales de Saint-Malo, Barcelona y Tarragona). Terminaremos este capítulo con 12 unidades procedentes de La Mata (11) y Denia (1).

En cuanto a los patrones que dirigían estas embarcaciones, algunas conclusiones podemos extraer de la documentación consultada; al ocasionarse diversas repeticiones de nombres a título individual. De entre todos los nombres exhumados destacaremos a Jaume García quien, a bordo de su barca, fondeó en el Grao de Valencia en cuarenta y seis ocasiones durante el periodo que estamos abordando, efectuando en el 90\% la ruta directa Alicante-Valencia; por lo que respecta a los artículos transportados, estos fueron de diferente naturaleza: pescado, cereales, sal, frutos secos, minerales y pequeñas cantidades de papel. En segundo lugar podemos destacar, a Francés García, posible familiar del anterior por la coincidencia en el apellido (aunque somos conscientes de que el patronímico García se repite con frecuencia, en los expedientes de la época), también podemos encontrar coincidencias en los artículos que trasladan, donde se mantienen las semejanzas; otro dato que les une es la tipología de la embarcación que utilizan, la barca, y por la periodicidad de sus viajes (aunque en el caso de Francés García se reduzca a la mitad). Otros potenciales parientes que ejercieron de patrones junto a los anteriores fueron Feliciano, Joseph y Pere Juan.

La saga de los García deja paso a los Font (Antoni, Francés y Maciá) que a bordo de sus naves transportarán importantes cantidades de pescado y cereal. También podemos rescatar aquellos personajes como Francés Barceló, Antoni Bernat, Antoni Blasco, Juan Jordá, Francés Parecha o Antoni Oliver, quienes guiaron sus respectivas naves en diferentes ocasiones hasta la dársena valenciana, donde desembarcaron desde géneros de primera necesidad (pescado y cereales) a materias primas (para la elaboración de telas), minerales (acero, plomo o hierro) y productos manufacturados (libros, espejos, papel o muebles). Junto a los patrones listados podemos destacar a Agustí Ventura, Grau Benrich, Jaume y Francés Catarla, Esteve Morillo o Batiste Paya que en cuatro u ocho ocasiones, individualmente, transportaron géneros en sus diversas fases de transformación. Esta nómina se podría completar con decenas de marinos diferentes 
que llegan hasta la ciudad del Turia al timón de sus respectivos buques. La carencia de argumentos secundarios en torno a estos personajes, nos imposibilita conocer su origen, información que nos ayudaría a relacionarlos, indagando los posibles lazos de parentesco que les unía o la simple casualidad de sus apellidos. Pero lo que sí podemos analizar a través de los libros del Peatge de Mar, es que la gestión de estos individuos no se restringía a dirigir su buque hasta su destino, sino que armonizaban este cometido con una intervención directa en la propia actividad mercantil, como se desprende de la presencia de numerosas partidas de mercaderías de su propiedad ${ }^{8}$.

Los productos exportados desde el puerto alicantino son de índole muy diversa, por lo que su estudio requiere de grupos homogéneos. Así, dentro de la multiplicidad de mercancías (superan el centenar de artículos diferentes) desembarcadas en la playa valenciana, subrayaremos en primer lugar los productos alimenticios de procedencia vegetal y animal. Los frutos secos (almendras y castañas peladas y con corteza, pasas, dátiles, avellanas y nueces) que llegan al Grao en cantidades destacadas; géneros bastante habituales en el conjunto de los buques provenientes de la costa meridional del Reino. En proporciones menores y según la estación, encontramos: higos, dátiles (en algunas partidas se detalla que proceden de Berbería) y prunas (en ocasiones se especifica que son para escaldar, posiblemente para confitura). Las leguminosas también forman parte de los cargazones por medio de remesas de algarrobas (durante el periodo temporal que estamos abordando se exportaron 2.502 @), garbanzos y, como anécdota, cabe reseñar la llegada de pequeñas cantidades de altramuces.

Los cereales, tan importantes en las importaciones valencianas, tienen una presencia destacada en las exportaciones alicantinas, fundamentalmente el trigo y la cebada, los verdaderos protagonistas de entre las gramíneas panificables; el resto sólo tiene una presencia testimonial (avena, mijo, alpiste o panizo). Ahora bien, por la importancia que adquiere el trigo en la economía municipal de la ciudad de Valencia ${ }^{9}$, que desvía importantes partidas de dinero para asegurarse el suministro anual de grano; adquiriendo y almacenando las necesidades estimadas según la población del momento ${ }^{10}$, y por la dependencia, casi obsesiva, del abastecimiento marino ${ }^{11}$ para satisfacer de pan las

8. Un ejemplo es la trascripción íntegra del siguiente asiento:

Dilluns XXII de setembre de 1642 patro Frances Colai ve de Alacant. Del Regne

Remitente El patro 6 quintals de panses.

Destinatario Per al dit.

(A. R. V.), (M. R.), (P. M.), 11.016, año 1642, f. sin numerar.

9. Braudel nos recuerda que las ciudades bañadas por el Mediterráneo pasaban constantemente por dificultades alimenticias, pero con la misma frecuencia restablecían el equilibrio de su vida, importando trigo. BRAUDEL, F., El Mediterráneo y el mundo mediterráneo en la época de Felipe II, I tomo, Madrid, 1993, p. 764.

10. Ibidem, Para F. Braudel estudiar los problemas del trigo,.....equivale a fijarse en una de las debilidades permanentes de la vida del Mediterráneo y al mismo tiempo, a abarcar esa vida en todo su espesor., p. 754.

11. La escasez en la producción triguera y el elevado coste del transporte terrestre desde las zonas productoras de la península (La Mancha, Aragón o Andalucía), hacían del mar el medio de transporte más rápido, eficaz, y económico por excelencia. 
mesas de los valencianos y, asimismo, debido a otros factores marcados por la carestía cerealícola secular valenciana, conviene profundizar en el desarrollo comercial de esta mercancía. Al analizar globalmente los resultados obtenidos en la documentación del Peatge de Mar para las importaciones de trigo entre 1626-1650, encumbran la zona sur del Reino hasta el cuarto lugar de los mercados suministradores ${ }^{12}$ de trigo con 38.792 cahices (el 10,9\% del total) ${ }^{13}$ con destino a la ciudad del Turia. De los puertos situados en el espacio comprendido entre Valencia y Pilar de la Horadada el mayor exportador de grano fue Alicante con un total de 15.212 cahíces lo que supone el 39,2\% del total; seguido de lejos por Denia y Villajoyosa con 4.872 (12,5\%) y 4.391 (11,3\%) cahíces respectivamente.

Sin duda el puerto alicantino acapara más de una cuarta parte de todo el trigo embarcado en los puertos del litoral acotado, pero veamos qué fluctuaciones expendedoras se originaron en las remesas enviadas desde Alicante; balance anual que hemos representado en el siguiente cuadro:

\section{Exportaciones marítimas de trigo Alicante-Valencia (1626-1650)}

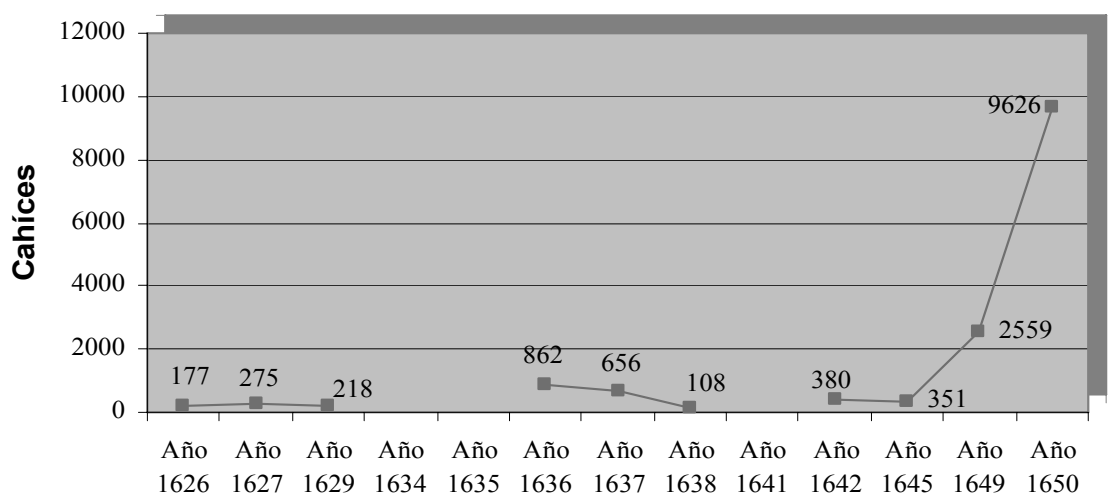

Los datos del gráfico nos permiten observar que, durante los años 1626, 1627 y 1629 , los envíos alicantinos de grano hacia Valencia no sufrieron variaciones significativas al contabilizarse, para cada año señalado, las cantidades de 177, 275 y 218 cahíces respectivamente, volumen suministrador que se concentro en los cuatro últimos meses del año, espacio temporal que podemos relacionar con la finalización de las labores de recogida, trillado y almacenamiento del grano junto con su consumo. El binomio 1634-1635 nos depara la primera de las dos cubetas depresivas que hemos observado a lo largo del cuarto de siglo que estamos estudiando. Este foso suministra-

12. Las tres primeras zonas de mayor a menores cantidades expedidas son: La Italia Insular y Peninsular con 162.607 cahíces, el Norte del Reino (desde la frontera catalana hasta Valencia) con 49.564 cahíces y Cataluña-Rosellón con 40.285. Datos extraidos de BLANES ANDRÉS, R., El puerto de Valencia: encrucijada de rutas, productos y mercaderes, Biblioteca Valenciana, Valencia, 2003, p. 128.

13. Ibidem, p. 136. 
dor será sustituido por un nuevo trienio: 1636, 37 y 38, que se iniciará con un volumen exportador muy significativo, si lo comparamos con el periodo anterior, al obtenerse 862 cahíces; el año 1637 marcará el inicio de un descenso progresivo al desembarcarse en el puerto valenciano 656 y 108 cahíces. Caída que nos abrirá las puertas de la segunda y última depresión, la de 1641. Finalizaremos este repaso del aprovisionamiento marino con dos ciclos bien diferenciadas; una primera fase, que podemos calificar de modesta, 1642-1645, donde las embarcaciones procedentes de Alicante trasladarán hasta Valencia 380 y 351 cahíces y una segunda, 1649-1650, en que se superan, con creces, todos los cargazones anteriores al anotarse 2.559 y 9.626 cahíces Exportaciones que se centraron en los primeros y últimos meses de los años señalados.

Este comercio marítimo pudo llevarse a cabo gracias a los hombres e instituciones que desde Alicante y Valencia fueron capaces de crear vínculos mercantiles, teniendo el trigo como embajador en ambos puertos. La dársena alicantina suministrará grano, por medio de exportadores como Palavesino que durante los dos últimos años de nuestro trabajo satisfará los pedidos de Escanio Sobregondi, Tomás Pere Calvillo, Juan Gabriel Gómez, Torregrosa o El Conde de Parcent. Por su parte Gaspar Sanz se vinculará, durante 1636, con Miguel Juan Peris, la Ciudad de Valencia, el Convento de la Trinidad y en ocasiones, él mismo, desempeñará el papel de remitente y destinatario. Les siguen Pere Roca y Escanio Sobregondi, expedidores y receptores que se autoabastecen ambos dos de cereal en 1650. Un caso digno de mención es la pareja formada por Juan Portillo y Francés Remoy que en una sola partida expedirán 5697 cahíces, sin lugar a dudas, la más importante de los años acotados. Otros mercaderes, que estarían englobados en un estadio inferior, por sus fugaces apariciones, fueron la familia Pascual (Alexandre, Francés y Miguel), Juan Gabriel Gómez o Vicente Arques.

Entre los destinatarios de los pedidos nos encontraremos al aludido Escanio Sobregondi, quien contactará, ampliando y completando sus adquisiciones, con Mositeli, Vicente Arques y el Conde de Ana. Pere Rafel (natural de Valencia y curtidor y vendedor de mantas) adquirirá grano por medio de Asensio Giner y Antonio Togores. El Conde de Elda lo encontraremos con Alexandre Pascual, Barberá y Miguel Peris. Juan Gabriel Gómez con Paulín y Palavesio. Finalizaremos con la Ciudad de Valencia que negocia con Gabriel y Gaspar Sanz. Un dato que llama la atención es el número de instituciones, religiosas y laicas, así como de dignidades nobiliarias, incluido el Rey, que intervienen en este mundo tan particular.

Un segundo cereal de características análogas al trigo fue la cebada. Si bien siempre ha estado asociado al forraje de los animales, el hombre con frecuencia lo ha incluido como parte de su dieta diaria; en efecto al lado del trigo, los otros cereales eran pan cotidiano en las mesas mediterráneas; sobre todo, la cebada y el mijo ${ }^{14}$. Este consumo no se ajustaba al área del Mar Interior, pues durante prolongados períodos el régimen nutritivo de los pobres se basaba en granos de diversa naturaleza. En la Europa del Norte prevalecía el centeno, en Inglaterra el principal cultivo cerealícola era el de la

14. BRAUDEL, F., El Mediterráneo y el mundo mediterráneo..., vol. I, p. 754. 
cebada, empleada tanto para la fabricación de cerveza como para el pan ${ }^{15}$. En Francia, Italia y España, el trigo se combinaba frecuentemente con diferentes granos (cebada, arroz, avena o el pan de castañas elaborado en Córcega). Harrison nos recuerda que en la Inglaterra de 1577, era frecuente que por todo el campo el pan se hace con el grano que da la tierra; no obstante, la nobleza se abastece comúnmente del trigo suficiente para la propia mesa, mientras los de su casa y los vecinos pobres se ven obligados a contentarse con centeno o cebada, y muchos además, en épocas de escasez, con pan hecho de judías guisantes o avena, o todo junto y con algunas bellotas mezcladas ${ }^{16}$. James Casey nos recuerda que los valencianos fabricaban un pan, a principios del siglo XVII, con trigo de buena calidad mezclado con cebada y arroz ${ }^{17}$. Los testimonios precedentes nos llevan a especular que la cebada era un cereal utilizado frecuentemente en la mesa de los valencianos, especialmente en épocas de crisis de subsistencia donde escaseaba el trigo tenía que ser sustituido por grano de diferente calidad, pero igual de nutritivo.

Las importaciones valencianas de este árido, entre 1626-1650, se centraron en seis espacios del Mediterráneo occidental: el sur y norte del Reino de Valencia, la Italia insular y peninsular, Cataluña-Rosellón, archipiélago Balear y el norte de África. Alcanzándose un volumen total de 23.697 cahíces $^{18}$. De todas las áreas señaladas el primer lugar lo ocupa la zona meridional del Reino, exportando 10.650,5 cahíces, lo que supone el 46,2\% del total. El puerto más importante en estas transacciones, no cabe duda que es Alicante al facturar 7.116 cahíces; distribución anual que hemos plasmado en el siguiente gráfico:

\section{Exportaciones marítimas de cebada Alicante-Valencia}

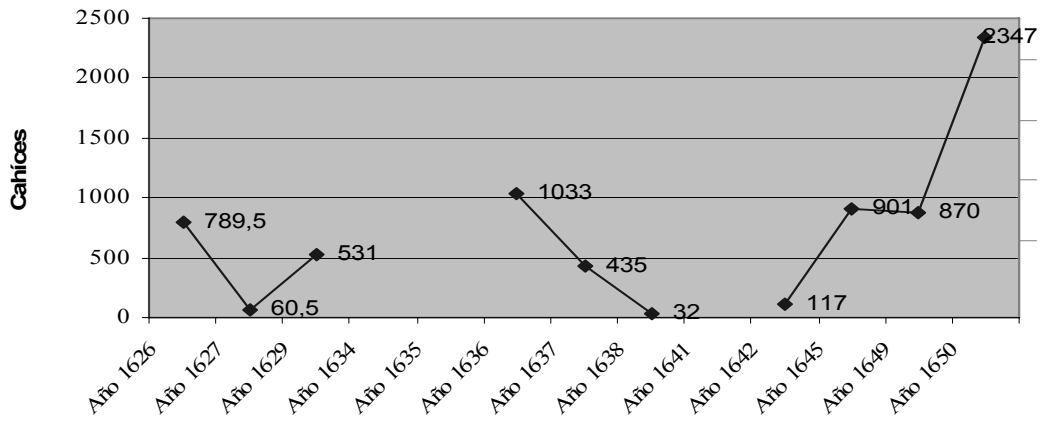

15. BLANES ANDRÉS, R., El puerto de Valencia: encrucijada.., p. 142.

16. Citado en William Ashley, The bread of our forefathers: an inquiry in economic history, Oxford, Clarendon Press, 1928, p. 58 y citado por CIPOLlA, C. M., ed. Historia económica de Europa. Siglos XVI y XVII, Barcelona, 1987, p. 96.

17. CASEY, J., El Reino de Valencia en el siglo XVII, Madrid, 1983, p. 58. Citado por BLANES ANDRÉS, R., El puerto de Valencia: encrucijada.., p. 142.

18. BlAnES ANDRÉs, R., El puerto de Valencia: encrucijada.., p. 143. 
Lo primero que nos llama la atención es la similitud existente, al comparar las exportaciones alicantinas de trigo y cebada, en las dos cubetas depresivas de 1634-35 y 1641, etapas donde no se anotará ninguna embarcación, que zarpando del puerto de Alicante, tuviera como destino el mercado valenciano.

Los años iniciales del segundo cuarto del Seiscientos (1626-1627-1629) principian con un volumen expendedor de 789,5 cahíces. Esta cifra se verá mermada al año siguiente, al producirse un descenso significativo que frenará al alcanzar los 60,5 cahíces; la porción más pobre del trienio, cerrándose con una ligera recuperación al obtener los 531 cahíces. La segundo etapa comercial (1636-38) se significará por sobrepasarse, inicialmente, los 1000 cahíces, guarismo que abrirá una caída en picado en los años sucesivos, cerrándose con el nivel más bajo de todo el período de 1626-1650, con 32 cahíces. El cuatrienio que cierra el proceso arranca con un perfil diferente a los dos periodos anteriores, al iniciarse con los niveles más bajos con 117 cahíces, extremo que marcará una recuperación progresiva hasta tocar techo en 1650 con 2347 cahíces.

De las personas vinculadas a este negocio, tanto desde la ladera exportadora como importadora, algunas están ligadas al comercio triguero, así podemos recordar los nombres de Paravecino que venderá un importante volumen de cebada, a los mismos comerciantes que habían adquirido trigo; durante los últimos años de nuestro estudio, destacando, de entre todos, el Conde de Parsent que recibirá 800 cahíces. Melchior Ortiz se pondrá en contacto con un variado número de hombres de negocios valencianos (Gaspar Sifres, Gaspar Sanz, Pedro Rejaulí o Vicente Cortés). Jaume Talagero centrará sus transacciones en 1629, destinadas a Constantín Cernesio, a Llacer del Mar $^{19}$ y al Marqués de los Vélez. Algunos otros mercaderes a tener en cuenta son los posibles parientes Berenguer (Batiste, Francés y Justino), Paulo Geroni Ribanegra o Agustí Hernández. Los mercaderes valencianos más destacados, que se beneficiaron de estas importaciones son los ya conocidos Cernesio (Constante, Francisco y Juan) unidos a los mencionados Paravecino, Ribanegra...y a Bertomeu Isula. Llacer del Mar estará ligado a Nicolau Escorsa, Gaspar Sanchos o Pere Bajón. Cerraremos este listado con Batiste Almansa que nos pondrá en contacto con sus afines alicantinos Diego Almansa, Girones Julio Escorsa o Alfonso Martínez.

Al igual que en el trigo hemos visto desfilar personas ajenas al oficio de mercader, licenciados, abogados, canónigos, frailes, condes, marqueses o el Virrey de Valencia.

Finalizaremos este análisis exportador de grano hacia Valencia, con la gráfica comparativa, entre el trigo y la cebada, elaborada a tal fin:

19. En la documentación consultada aparece escrito indistintamente como «Llacer del Mar o «Llacer del Mor». 


\section{Gráfica comparativa en las exportaciones de trigo y cebada de Alicante a}

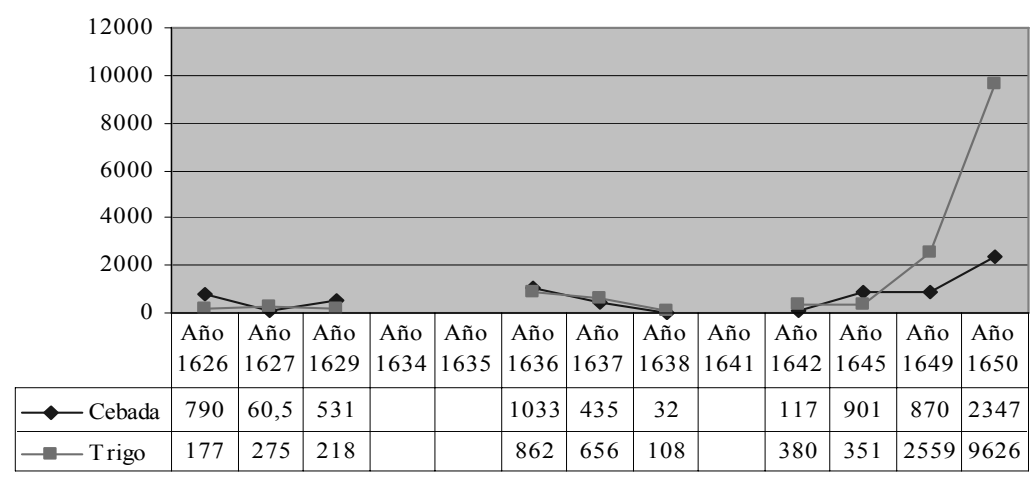

Aunque el trazo dibujado es lo suficiente expresiva no podemos dejar de ilustrarlo brevemente; al leerlo la primera información que nos ofrece es la existencia de las dos cubetas profundas señaladas con anterioridad, intercaladas entre tres espacios temporales donde las llegadas a la playa del Grao de Valencia, de cereales y trigo, procedente de Alicante, fueron significativas para el conjunto importador valenciano de áridos. Observándose, entre ambas gramíneas, una similitud en las dos primeras facetas, diferenciándose notablemente en la última, al cerrarse el ciclo con la llegada de importante cantidades de trigo.

Concluiremos el capítulo alimenticio, con la mención, a título meramente anecdótico, de algunos asientos de alpiste, alcaparras y olivas.

Un apartado muy interesante es el reservado al pescados y salazones ${ }^{20}$, en muchos países de Europa (en especial los situados en las costas, al lado de una vía fluvial o cerca de un lago) el pescado, no sólo jugaba un papel primordial en la dieta de las personas, sino en el conjunto de las importaciones alimenticias. El pescado fresco era mucho menos importante que el seco o salado, debido a las dificultades que tenía su conservación, sólo se transportaba a cortas distancias. En Valencia, cerca del litoral, se practicaba no sin peligros, la pesca destinada a surtir el mercado diario;.. y sus puestos de venta eran celosamente vigilados por un funcionario municipal,...con el fin de evitar que se vendieran partidas en mal estado de conservación ${ }^{21}$. Por tanto el comercio marítimo de este producto se basaba, mayoritariamente, en exportaciones de pescado manipulado convenientemente para que alcanzara los puertos de destino en buenas condiciones. Así, a modo de ejemplo, Barcelona se proveía de bacalao del

20. Enrique Jiménez López, nos recuerda que: El comercio de la pesca salada era uno de los fundamentos económicos del Alicante del setecientos. GIMÉnEZ LÓPEZ, E., Alicante en el siglo XVIII. Economía de una ciudad portuaria en el antiguo régimen, Institució Alfons el Magnànim, Diputació de València, Valencia, 1981, p. 367.

21. Castillo, A., Tráfico marítimo y comercio..., p. 119. 
Atlántico a través de embarcaciones bretonas y de sardinas y atún de la costa del Norte de África por medio de pescadores portugueses.

Por necesidad o por obligación, el pescado, especialmente el salado, tuvo una aceptación enorme durante el Seiscientos. Su consumo, como es sabido, se incrementaba durante los dilatados ciclos de prescripción canónica de la Iglesia católica; era importante el número de entidades religiosas, conventos, monasterios y hospitales que lo consumían como parte habitual de su dieta diaria, y estaba al alcance de la mayoría de la gente. Como es lógico la miseria incrementaba obligatoriamente los días de ayuno. En 1629 los jurados de Valencia afirmaban que la gent humil el consumeix encara que sia en dies que no són de dijuni ni abstinència de carnn ${ }^{22}$. Según E. J. Hamilton el consumo de pescado absorbía el 5\% del salario de una familia media. Como ya hemos comentado los salazones se consumieron masivamente por la población más humilde, debido a lo asequible de su precio y le permitía cubrir sus necesidades nutricionales en proteínas animales. Las clases más pudientes solían abastecer sus despensas, no sólo de pescado seco, sino de pescado fresco (marino o fluvial ${ }^{23}$ ), de calidad superior (congrio, merluza, trucha, salmón,...) y por lo tanto más caro ${ }^{24}$. El volumen de pescado desembarcado en el Grao superó a cualquier otro producto de importación, a excepción del trigo.

La importancia económica y los beneficios que se obtenían del comercio del pescado salado queda reflejada en la carta que un mercader alicantino escribió a su agente en 1661: en la pesca se pesca mucho dinero ${ }^{25}$.

El papel desempeñado por el puerto Alicante como centro distribuidor de salazones a Castilla $^{26}$, no se circunscribe a esta área geográfica, sino que su función expendedora se ampliará a otras zonas costeras del Reino de Valencia entre las que se incluye el Grao valenciano, facturando grandes sumas de pescado, fundamentadas en la trilogía formada por el bacalao, la sardina y el atún.

De las especies mencionadas, el bacalao, destaca en las exportaciones alicantinas por las importantes remesas comercializadas hasta el puerto de Valencia. Esta variedad irrumpió en el mercado valenciano, aproximadamente, en el último tercio del Quinientos. Era uno de los pescados más baratos que se importaba en libras, y por

22. ZuCChitello, M., Homes, vaixells i mercaderies de Tossa al Grau de València (1459-1703), Blanes, 1991. p. 189.

23. Los peces de rio en general no llegan a suponer un $20 \%$ de todo el pescado fresco y no alcanzan apenas un $7 \%$ del total... Los pescados de río ocupaban una posición muy secundaria en el consumo. Bernardos SANZ, J. U., «El abastecimiento y consumo de pescado en Madrid durante el Antiguo Régimen», Madrid, 1998., p. 12.

24. La Casa Real tenía su propio sistema de suministro, que servía para obtener una gran variedad de especies. Los menús de vigilia eran muy variados, como muestra por ejemplo la gran variedad que se condimentan para la cena de víspera de Nochebuena de 1695, donde incluyen truchas en escabeche, ostras, besugo, merluza y hasta tortugas y ranas. SiMÓN PALMAR, M. C., «La alimentación en el alcázar de Madrid y sus circunstancias», Madrid, 1982, Instituto de Estudios Madrileños, p.33.

25. ZuCCHITEllo, M., Homes, vaixells i mercaderies..., p. 189.

26. GIMÉNEZ LóPEZ, E., Alicante en el siglo XVIII. Economía de una ciudad portuaria ..., p. 367. 
su naturaleza concentrada era incluso el negocio más grande por caloría. Entre 1590 y 1640 constituian un cuarto del mercado, después este porcentaje creció hasta aproximadamente un $40 \%{ }^{27}$.

Las transacciones de bacalao fueron una constante a lo largo de la Edad Moderna y su mercado fue muy disputado por ingleses y bretones, especialmente, y en menor medida por irlandeses. Pensamos que la presencia de embarcaciones y marineros del Océano en el comercio entre Terranova y Alicante fue algo totalmente corriente en el período que nos ocupa ${ }^{28}$.

El hábitat natural de esta especie se sitúa en las frías aguas del Atlántico septentrional, en el mar del Norte y en el Báltico. Las importaciones de abadejo fueron una constante a lo largo del Seiscientos, procedente en su mayor parte de los bancos de Terranova. Su pesca tenía lugar durante los períodos de invierno (coincidiendo con el desove) y en verano (cuando emigran buscando su alimento).

Un importante número de puertos del Atlántico intervinieron en las empresas que anualmente partían hacia los lejanos bancos, y gran parte de ellos se sustentaba de los beneficios que se extraían de estas expediciones, movilizando la industria y el capital de amplias zonas, incluso del interior de sus costas. ${ }^{29}$

Las naves solían zarpar hacia los bancos del septentrión entre los meses de febrero y abril, las más rápidas solían iniciar el regreso hacia junio (para especular con los altos precios de principio de campaña), pero el grueso de la expedición no lo hacía hasta finales del verano o principio del otoño. Por la distancia a atravesar y los inconvenientes de la travesía, la mayoría de los pesqueros de Terranova no comenzaban a llegar a nuestro puerto hasta principios de noviembre, los primeros, y los últimos lo hacían en la primera quincena del mes de febrero. Llenaban rápidamente las bodegas, la mayor de las veces de lana, y regresaban a sus puertos de origen con el tiempo justo para preparar la siguiente campaña.

El total de adquisiciones, remitidas hasta nuestra playa desde las diversas zonas que nos han proporcionado los manuscritos del Peatge, las hemos recogido en los cuadros adjuntos:

27. Ling, R., Movimientos a largo plazo en el comercio de Valencia, Alicante y el oeste del Mediterráneo..., p. 225 .

28. [...], ya en 1578 se registran llegadas de salazón inglés a puerto con destino al interior peninsular [...] Las pesquerías de Terranova, explotadas desde los inicios del XVI [...] se habian convertido en el principal proveedor de bacalaoa España desde los primeros años del siglo XVII. GIMÉNEZ LÓPEZ, E., Alicante en el siglo XVIII. Economía de una ciudad portuaria ..., p. 367.

29. Trocme, E. y Delafosse, M.: Le commerce rochelais de la fin du XVI siècle au debut du XVII, París, 1952, p. 122. 


\begin{tabular}{|l|r|r|}
\hline a) Área Mediterránea: & \multicolumn{1}{|c|}{ ( } & Unidades \\
\hline Sur del Reino & $\mathbf{9 6 7 1 4}$ & \\
\hline Francia-Mediterránea & 15163,5 & 20748 \\
\hline Italia Insular-Peninsular & 4495 & \\
\hline Norte del Reino & 1747 & \\
\hline Castilla Mediterránea & 1572 & \\
\hline Archipiélago Balear & 1372 & \\
\hline Cataluña-Rosellón & 824 & \\
\hline Total & $\mathbf{1 2 1 8 8 7 , 5}$ & $\mathbf{2 0 7 4 8}$ \\
\hline
\end{tabular}

\begin{tabular}{|l|r|}
\hline a) Área Atlántica & \multicolumn{1}{|c|}{ a } \\
\hline Terranova & 73152 \\
\hline Inglaterra e Irlanda & 34058 \\
\hline Francia Atlántica & 5237 \\
\hline Portugal & 820 \\
\hline Castilla Atlántica & 8 \\
\hline Total & $\mathbf{1 1 2 4 5 5}$ \\
\hline
\end{tabular}

Como podemos observar las exportaciones procedentes de los puertos del sur del reino son las más destacadas de los dos espacios marítimos concretados en el cuadro. De entre todo el encadenamiento de dársenas situadas en litoral meridional, resalta la de Alicante al monopolizar más de la mitad de las expediciones portadoras de bacalao, concretamente $51.546 @$ lo que supone el 53,3\%, con destino a la ciudad del Turia.

Las cantidades anuales manufacturadas desde el puerto alicantino dibujan una gráfica irregular, donde podemos observar cómo se intercalan periodos alcistas con caídas significativas, así como intervalos donde la balanza exportadora es nula:

\section{Exportaciones alicantinas de bacalao a Valencia (1626-1650)}

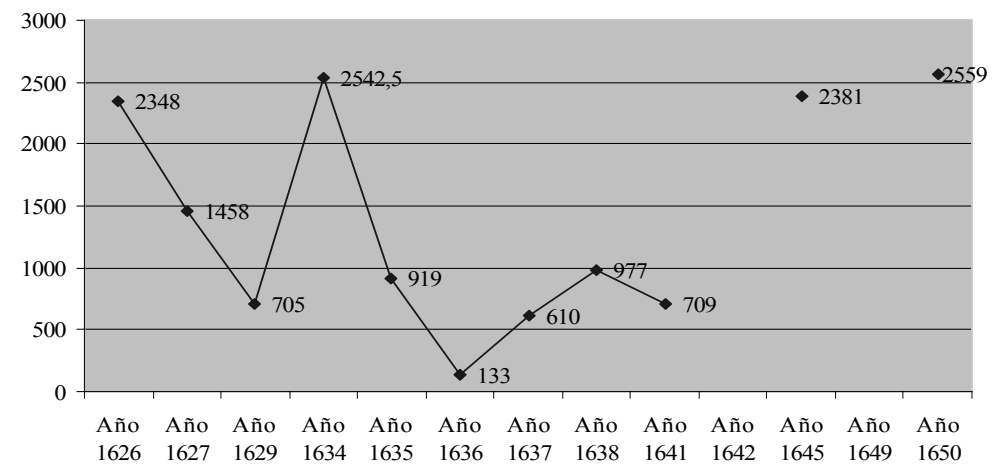


En líneas generales, se advierten cuatro años repartidos irregularmente (1626, 1634, 1645 y 1650) que superan las $2000 @$, seguidos de 1627 donde rebasa con creces el millar, un tercer ciclo, integrado por 1629, 1635, 1637, 1638 y 1641, cuyas remesas se encuentran en una orquilla que oscila entre las 500 y $1000 @$. Por último cerraremos este somero análisis de los años 1642 y 1649, lapso temporal donde no se ha registrado actividad exportadora. Los envíos tenían lugar en el cuatrimestre formado por los meses de noviembre diciembre, enero y febrero.

Las personas que intervienen en este comercio son numerosas, al poseer datos sobre los mercaderes expendedores y destinatarios, nóminas que nos dan una visión aproximada de lo que fue este mundo de las transacciones donde el protagonista principal era el bacalao. Grupos formados por numerosos hombres de negocios tanto en la vertiente alicantina como valenciana, de los que hemos rescatado los más descollantes por su número de intervenciones en el ejercicio de su trabajo o por las cantidades tramitadas o percibidas. El estudio de estos marchantes nos obligará, en primer lugar, a situarnos en el puerto alicantino, donde nos relacionaremos con personajes como Don Jaume Talagero que a lo largo del proceso enviará diversas pedidos destinados en su mayor parte a Llacer del Mar; centrándose su trabajo en los meses de noviembre y diciembre de 1627, 1629 y 1634. La importancia de Don Jaume Talagero será compartida con Paulín Guillermo, quien desempeñará su oficio exportador durante los meses de enero y febrero de la década de los años treinta, y sus receptores en la playa del Grao serán los parientes Domingo y Luis Ignacio Royo y Domingo López. Con menor presencia hemos podido rescatar a los familiares Miquel y Joaquín Melchor, individuos que desarrollarán su ofició en los años veinte, remitiendo toda su mercancía al ya mencionado Llacer del Mar. Romero a nivel individual lo hemos encontrado realizando negocios con Glaudi Combas y Pere y Gaspar Valles a lo largo de 1634. A título meramente anecdótico, nombraremos a Miquel Jacinto y Antonio Morelles que no sólo despacharán pequeñas cantidades de bacalao, sino que los encontraremos vinculados con exportaciones de otras especies como la sardina y el atún, donde alternan con los grandes mercaderes alicantinos del pescado.

De entre los mayoristas asentados en la urbe valenciana que reciben el bacalao remitido desde la capital alicantina resaltaremos a Llacer del Mar, comerciante que se relacionará con los proveedores alicantinos más destacados, como hemos podido comprobar con anterioridad, aunque la lista la podemos completar con los nombres de otros tantos como son Nicolás y Diego Escorsa, Carlos Papín (posiblemente italianos) y Vicente Miró. Las embarcaciones consignadas a Llacer del Mar llegaron a Valencia durante los años veinte y, ocasionalmente, en 1634 y 1641. Los negocios de este mercader no se circunscribieron al bacalao, detectándose su presencia en la adquisición de considerables partidas de sardinas y atún. Otros destacados nombres son Juan Batiste Moiselo y los aludidos Pere y Gaspar Valles, Domingo y Luis Ignacio Royo y Domingo López.

La sardina era, y es, una especie habitual del mar Mediterráneo y del océano Atlántico europeo, y sólo esporádicamente la encontramos en aguas septentrionales. Se pesca activamente durante la primavera y el verano, épocas donde se forman los 
bancos mayores ${ }^{30}$. Constituye una de las especies económicas más importantes de la costa de la península Ibérica y se consumía fresca y en conserva (en salazón, escabeche, aceite,...).

Este alimento, tan popular, solía llegar, en cantidades importantes, al mercado valenciano en el último trimestre del año y los meses de enero, febrero y marzo del año siguiente, paralizándose, en ocasiones, su importación durante la primavera y el verano, épocas donde se realizaban las capturas más importantes y en ocasiones excepcionales se consumía fresco.

Los escribanos, encargados de asentar los variados artículos que iban llegando por mar, contabilizaban las sardinas en unidades, con fines fiscales ${ }^{31}$, detallando también los diferentes recipientes que las contenían (botas, barriles, barrilets, balas,...) junto a diversas medidas y pesos (quintales, arrobas, cuartos, cahíces,...). Gracias a la minuciosidad con que se anotaban las distintas partidas hemos podido distinguir diversas variedades, y su estado de conservación: sardineta, en caldo y per a esc (sardina para cebo).

Según los documentos del Peatge las importaciones de sardinas entre 1626 y 1650 a partir del volumen desembarcado anual, han arrojado los siguientes resultados ${ }^{32}$ (las primeras líneas las hemos destinado a los resultados menos significativos, como el estado de preservación, la condimentación y transformación):

La sardineta llegó en una sola ocasión hasta la playa valenciana, bajo la tutela del patrón-comerciante Francés Torres que desembarcará $9 @$ el 13 de enero de 1626. La sardinas en caldo, se les menciona en una sola oportunidad. El patrón Jaume Colet, a bordo de su laúd, trasladará y comercializará $30 @$ (03 de febrero de 1645); al desem-

30. El peix blau, el més abundant i el més econòmic, era consumit intensament, fresc o salat. Es un peix estacional. Les sardines i les anxoves, aplegades en bancs compactes s'atansen cap a la costa la primaveraestiu. Els verats formen bancs pelàgics, sobretot a l'abril, i també el setembre-octubre. Aquests sóns els moments favorables per a pescades abundants. ZUCCHITELLO, M., El comerç marítim de Tossa a través del port barceloní (1357-1553), Quaderns d'Estudis Tossencs, nº 2, Barcelona, 1994, p. 105.

31. Entre los diversos oficios que se ejercían en la playa del Grao, estaba el de contador de sardinas, que ayudaba al escribano a llevar un control sobre dicho pescado. En referencia a dicho oficio podemos leer el nombramiento aprobado por los Jurados de la ciudad el 24 de abril de 1636:...Attes que per mort de Vct Ramos qui tenia una plaça de contador de sardines vaca Per ço elegeixen y nomenen a Bertomeu Gratell en dita plaça de contador de sardines ab los per casos y emoluments a dita plaça...

Jacinto Sadorni verguer ell huy haver posat en possessio a Bertomeu Gratell en la dita plaça de contador de sardines fent lo contar sardines en señal de la verdadera real possessio adaquell donada de dita plaça de contador de sardines. A.M.V., M.C., 1635-1636, A-162, f. 716 r. y 717 a.

Otro ejemplo nos lo proporcionan las mismas fuentes el 20 de febrero de 1638: Los señor Jurats Racionals y Vicent Sanz Boil ciutada sindich de la ciutat de Valencia excepte los señor Jurats Gaspar Juan Catala generos y Melchior Cerdan ciutada absents del present acte a justats en la sala daurada. Attes que al present vaquen moltes plaçes de contadors de sardines. Per ço elegeixen y nomenen a Joseph Monço guardia de la plaça de les sadines en contador de sardines ab los percaços y emoluments a dita plaça de contador de sardines. A.M.V., M.C., 1637-1638, A-164, f. 542.

32. Hemos tratado de reducir a una sola unidad los diferentes pesos, medidas, etc..., dejándolos reducidos a sólo dos magnitudes: arrobas @ y unidades U. 
peñar al mismo tiempo el papel de remitente y destinatario. La sardina inscrita con el sobrenombre de per a esc, se distribuyó mayoritariamente desde el Reino de Valencia especialmente desde Alicante, contabilizando un total de 6 partidas, que suman $95 @$, distribuidas entre los meses de julio y agosto de 1626, 1645 y 1650. De los hombres de negocios que intervinieron, destacaremos a Juan Batiste Palavesino que se relacionó con los pescadores valencianos Vicent Ortola y PereAranda.

A continuación abordaremos el apartado fundamental de este capítulo, la exportación de sardinas propiamente dichas. En primer lugar recordaremos, al igual que hicimos con el bacalao, las zonas expedidoras de esta artículo en relación a la playa del Grao, como en anteriores ocasiones las dos áreas serán la mediterránea y la atlántica:

\begin{tabular}{|l|r|r|}
\hline a) Área Mediterránea* & Unidades & \multicolumn{1}{|c|}{ @ } \\
\hline Cataluña-Rosellón & 12070170 & 10891,5 \\
\hline Sur del Reino & $\mathbf{9 3 8 4 0 2 5}$ & $\mathbf{5 3 8 3 0}$ \\
\hline Francia-Mediterránea & 1183200 & 1272 \\
\hline Italia Insular y Peninsular & 687300 & 3354 \\
\hline Norte del Reino & 665000 & 541 \\
\hline Norte de África & 406100 & 58 \\
\hline Archipiélago Balear & 353000 & 204 \\
\hline Castilla Mediterránea & 172000 & 4476 \\
\hline Total & $\mathbf{2 4 9 2 0 7 9 5}$ & $\mathbf{7 4 5 3 6 , 5}$ \\
\hline
\end{tabular}

\begin{tabular}{|l|c|r|}
\hline a) Área Atlántica & Unidades & \multicolumn{1}{c|}{ @ } \\
\hline Castilla Atlántica & & 4406 \\
\hline Portugal & 2655116 & 26542,5 \\
\hline Inglaterra e Irlanda & 1452800 & 131150,5 \\
\hline Francia Atlántica & & 49915 \\
\hline Total & $\mathbf{4 1 0 7 9 1 6}$ & $\mathbf{2 1 2 0 1 4}$ \\
\hline
\end{tabular}

Aunque las cantidades son de por sí lo bastante expresivas, merecen cierta explicación. Puede sorprender en principio, la dimensión que alcanzaron las remesas de sardina procedente del resto del Reino, zona donde esta variedad de pesca era limitada. La propia documentación desvela la duda, al señalar que estos envíos con destino a nuestra ciudad eran a su vez reexportaciones procedentes de espacios más distantes. Algunas partidas originarias de Alicante y Denia procedían a su vez de puertos bretones, ingleses e irlandeses. Centrándonos en el espacio meridional del Reino y más concretamente en el puerto alicantino, las cifras obtenidas son muy significativas; así Alicante entre 1626-1650 comercializará 5.581.001 unidades (lo que supone el 60\% de la sardina expedida desde dársenas emplazadas en litoral austral)y 13.773 @ (lo que se traduce en un 25,6\%), cantidades significativas que nos sugieren la importancia de estas transacciones. Pero quiénes hacen posible este activo y lucrativo negocio, lo primero que llama la atención, es la falta de continuidad, en el tiempo, de estos

* BLANEs ANDRÉs, R., El puerto de Valencia: encrucijada de..., pp. 147 y 148. 
individuos y la rapidez que ocupan su lugar nuevos personajes que a su vez desaparecen dejando paso a otros nuevos. De esta renovación continúa, podemos rescatar a Jacinto Miquel que centrará sus apariciones en el mes de diciembre de 1627, enviando 1.511.401 unidades a Llacer del Mar. Antoni Morelles protagonizará diversas expediciones en enero de 1635 destinadas a diferentes mercaderes valencianos (Pere y Gaspar Valles, nominados con anterioridad, Joseph Coll, Juan Gisbert, Bertomeu Anteume y Frances Reus). Nicolas Nico lo encontraremos en 1649 y 1650 abasteciendo a la pareja Manuel Botaso y Frances Rato. Por último, no podemos dejar de referirnos a dos personajes que los localizaremos en la compra-venta de las otras dos especies reinas de este trasegar marítimo; Jaume Salvador que hará las funciones de remitente y destinatario durante el bienio 1635-36 y Jaume Talagero presente en la segunda mitad de los años veinte, despachando género para Llacer del Mar.

El índice de receptores valencianos está encabezado, de nuevo, por Llacer Del Mar o Del Mor que se encadenará con diversos vendedores afincados en Alicante, entre los que se encuentran, no sólo los ya citados con antelación, sino otros como Tomás Toledo, Ricardo Onzell y Felip Peris. En menor volumen de transacciones le siguen Pedro Albuxeres, Batiste Almansa y Vicente Salvador.

Esta trilogía de especies comerciales de pescado la clausuraremos con el atún, pez común al Atlántico y al Mediterráneo y que se reproduce en este último mar. Según la variedad (rojo o blanco), la puesta la suele hacer en primavera cerca de las costas de Cerdeña, Sicilia y Túnez o en el litoral español. Pescado desde la más remota antigüedad con destino al consumo fresco, en salazón o en conserva, es una de las variedades más abundantes en aguas valencianas, especialmente en la parte meridional del Reino. Aprovechando las migraciones genéticas del atún, que se aproxima a la costa en los inicios del verano, se realizaban las capturas y una vez salado se comercializaba. Agosto y septiembre eran, [...], los meses en que el tráfico de embarcaciones atuneras era mayor ${ }^{33}$.

En el litoral alicantino existían en la época almadrabas destinadas a su captura y preparación, de las cuales la Corona obtenía también sus beneficios fiscales. En las tierras del marquesado de Denia existieron pesquerías cuyo funcionamiento fue regulado en 1602 y 1603 por sendos privilegios del valido duque de Lerma ${ }^{34}$. Pesquerías que funcionan durante la época que estamos analizando, tenemos múltiples referencias en la documentación manejada, especialmente, la almadraba de Denia, de la que se importan pequeñas partidas en 1629.

El mercado esencial para el abastecimiento de atún a Valencia fue el ribera Sur del Reino (Denia, Gandia o Alicante), el litoral insular y peninsular italiano (dentro de éste brillaron con luz propia, por el volumen exportado, las islas de Cerdeña y Sicilia).

Otros grandes mercados atuneros en estos años fueron la Castilla Atlántica (con las almadrabas gaditanas) y Portugal (especialmente los puertos situados al sur y centro

33. GIMÉnEZ LÓPEZ, E., Alicante en el siglo XVIII..., p. 375.

34. CASTILlo, A.:Tráfico marítimo y comercio..., pp. 119-120. 
del litoral lusitano, como Faro, Lagos, Lisboa o Setúbal) como podemos comprobar en el siguiente parrilla:

\begin{tabular}{|l|r|}
\hline \multicolumn{1}{|c|}{ a) Área Mediterránea: } & \multicolumn{1}{c|}{ @ } \\
\hline Sur del Reino & 12270,5 \\
\hline Italia Insular-Peninsular & 5158,5 \\
\hline Cataluña-Rosellón & 2413 \\
\hline Archipiélago Balear & 1424 \\
\hline Castilla Mediterránea & 991 \\
\hline Norte del Reino & 236 \\
\hline Norte de África & 166 \\
\hline Malta & 37 \\
\hline Total & $\mathbf{2 2 6 9 6}$ \\
\hline
\end{tabular}

\begin{tabular}{|l|c|r|}
\hline a) Área Atlántica & (a) & unidades \\
\hline Castilla Atlántica & 34564 & 65 \\
\hline Portugal & 13364 & \\
\hline Total & $\mathbf{4 7 9 2 8}$ & $\mathbf{6 5}$ \\
\hline
\end{tabular}

El atún era un producto bastante habitual en los cargazones alicantinos, sólo en dos ocasiones faltaron a esta cita, 1627 y 1645, años donde no se asentó, en los manuscritos citados, ningún registro relacionado con el tema que estamos comentando. Tesis que podemos comprobar al observar el gráfico adjunto:

\section{Exportación de atún Alicante-Valencia (1626-1650)}

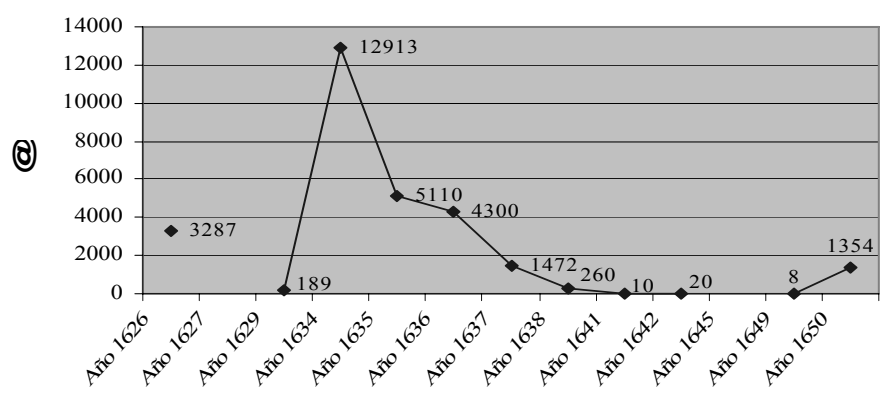

Al examinar la representación lineal lo primero que nos llama la atención es el espectacular ascenso de las exportaciones que se produce en 1634, al pasar de 189 @ en 1629 a $12.913 @$ @, techo que marcará el punto de inflexión de los envíos alicantinos hacia Valencia, que bajo ninguna circunstancia volverán a alcanzar la meta señalada. El lado opuesto lo encontramos en 1649 con tan sólo 8 transacciones.

Los animadores más destacados desde la vertiente alicantina, que hicieron posible este trasiego, los podemos reducir a tres; encabezados por Dionis Ortiz que durante el mes de septiembre de 1626 desembarcará importantes cantidades de atún destinadas 
única y exclusivamente a Francés Pisa. Francisco Rodrigo, centrará sus actuaciones en enero y febrero de 1626, relacionándose en todos las ocasiones con el comerciante valenciano Manuel Fernández Blandón. El tercer lugar lo ocupa Juan Batiste Truco que se enlazará con frecuencia con el italiano, avecindado en Valencia, Juan Batiste Caponi, durante los meses de septiembre y octubre de 1629, 1634 y 1635 . Otros tantos son Joseph Benito o Antoni Bisbal que desempeñan la doble función de vendedores y compradores.

Además de los importadores valencianos mencionados anteriormente, añadiremos a los conocidos Llacer del Mar, Vicente Salvador y Jaume Talagero al intervenir en la compra de este artículo a pequeña escala.

También, aunque en cantidades menores, aparecen las anchoas, el boquerón, la merluza, el congrio, la mussola salada y el nombre genérico de pescado (sin especificar la especie).

La fauna terrestre está representada por becerros (durante 1629, 1635 y 1650 se adquirirán por parte de Valencia 9240 cabezas $^{35}$ ) y algunos lechones y cerdos, bajo ninguna otra circunstancia se alude a animales de otra especie; en cuanto a los productos cárnicos son mencionados en diversas ocasiones el cerdo y sus derivados con señaladas partidas de embutido (sobrasadas y blanquet), en menor cuantía arriban, longanizas, manteca, quesos, miel y algún pernil. Las especias y condimentos, representados por la sal (de la Mata), la canela y la pimienta. La sección reservada a líquidos, aunque su aparición resulte esporádica, esta constituida por pequeñas cantidades de aceite de oliva y linaza. El capítulo alimenticio lo cerraremos con productos semitransformados o elaborados como el azúcar (piló, roig i moscovat), los turrones, el arrope, las confituras y pan de higo.

Los textiles en sus distintos grados de mutabilidad, desde la materia prima hasta la prenda más elaborada, se despliegan por medio de referencias a la fibra de esparto, la lana, el lino, y la seda en bruto; la mercería, telas de diferentes clases (camelote, estameñas, fustán, anacote), ropa usada, bayetas, trapos (usados y de colores), cintas, medias (de lana y de seda), lienzos, delantales, alfombras, etc. Los curtidos están presentes por medio de señaladas cantidades de pieles (grandes y pequeñas) de cabrito (adobades de blanquer), de ternero y de toro (con pelo y solano).

La madera manipulada es habitual en los cargazones alicantinos sobresaliendo por su abundancia las sillas (de nogal, de moscovia o de hilo), bufetes, escritorios, mesas de Flandes, baúles, cajas (grandes y pequeñas), camas de campo, mesas, bufetes, arquimesas, sillas, escritorios, remos, rayos de carro y pipas para fumar.

La cerámica (cazuelas, librillos y búcaros); la alfarería, que en los manuscritos se les denomina obra de terra, (ladrillos: grandes y pequeños) y cristales (anillas, tazas, botones, cristales sin especificar su finalidad y espejos).

35. De todos los asientos donde figuraban las cantidades de becerros exportados resalta el fechado el diez de noviembre de 1635 donde Don Julio Escorsa envía 3384 animales destinados a Batiste Almansa. 
Los metales y los minerales tendrán una presencia destacada, marcada por los acontecimientos políticos que tuvieron lugar a lo lago del cuarto de siglo que estamos analizando. Recordemos que eran un género registrado como mercancía de guerra (muy especialmente la trilogía formada por el plomo, el estaño y el cobre) sobre ellos se abatía la prohibición de salida de los centros exportadores cuando el horizonte político se nublaba ${ }^{36}$. El Reino de Valencia, a partir de 1635 y hasta finalizar la primera mitad del Seiscientos, se encontró inmerso dentro del área de influencia de algunos de los acontecimientos bélicos más determinantes del reinado de Felipe IV. El hierro, el acero, el estaño, la pirita y el plomo, en su ciclo más primario, tienen una presencia desigual en algunos de los años investigados. ${ }^{37}$ Estos artículos tendrán diferente consideración en las exportaciones alicantinas, pudiéndolos dividir en dos grupos bien diferenciados, el hierro (común, en barrita y grueso), el cobre, el estaño y el mercurio los incluiremos en el conjunto de metales con poco peso específico dentro de los navíos procedentes del puerto alicantino. Por el contrario, el acero y el plomo tendrán un apartado destacado en las ventas destinadas a la dársena valenciana. El acero, aunque no poseemos los datos necesarios, pensamos que es el objeto de una serie de transacciones llevadas a cabo mediante reexportaciones procedentes del litoral inglés e italiano. El volumen de este producto, comercializado desde Alicante casi alcanza las 10.000 @(9.963 @) distribuidas de forma desigual a lo largo del proceso, como podemos comprobar en la gráfica que presentamos a continuación:

\section{Exportaciones de Acero Alicante-Valencia (1626-1650)}

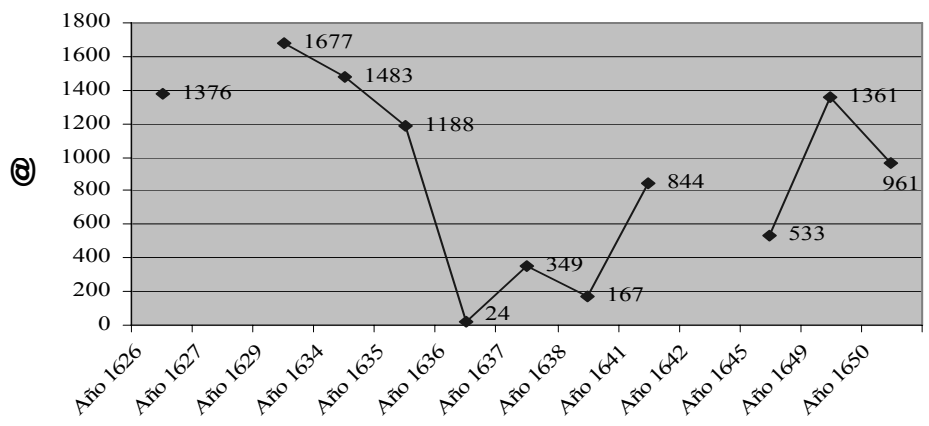

La lectura del trazo obtenido nos lleva a apreciar una fase que supera con creces las mil @ (los años iniciales, a excepción de 1627, en que no se detecta ningún envió, y 1649), siendo su extremos 1629 y 1635 . Por el contrario, los años centrales, son los que registran un debilitamiento más acentuado, al no superar la barrera del millar de @ (manifestándose el año 1636 como el más exiguo y 1650 como el techo de esta etapa). De los mercaderes, en origen, vinculados con este género descuellan Bertomeu Isula

36. Castillo Pintado, A., Tráfico marítimo y comercio de importación ..., p. 148.

37. BLANES ANDRÉS, R., «El tráfico exportador marítimo entre Barcelona...», p. 729. 
que aprovisionara a Pedro Sualles y a los italianos Escanio Sobregondi, Constantín Cernesio (caballero de origen milanes) y Juan Batiste Caponi. Juan Moscateli (además de Caponi y Cernesio) contactará con los familiares Blai y Manuel Botaso y Pedro Diego y por último señalaremos al apuntado Juan Batiste Caponi que interpretará el doble papel de remitente y destinatario.

Los receptores valencianos más concurrentes son la saga de los Botaso (Blai, Agusti, Juan Batiste y Manuel), Cosntantín Cernesio ${ }^{38}$, Juan Batiste Caponi y Juan Batiste Moiselo.

El plomo encabeza las exportaciones de metales al rozar las $28.000 @$ (exactamente 27.967), con una distribución anual bastante desigual como nos lo muestra el cuadro anexo.

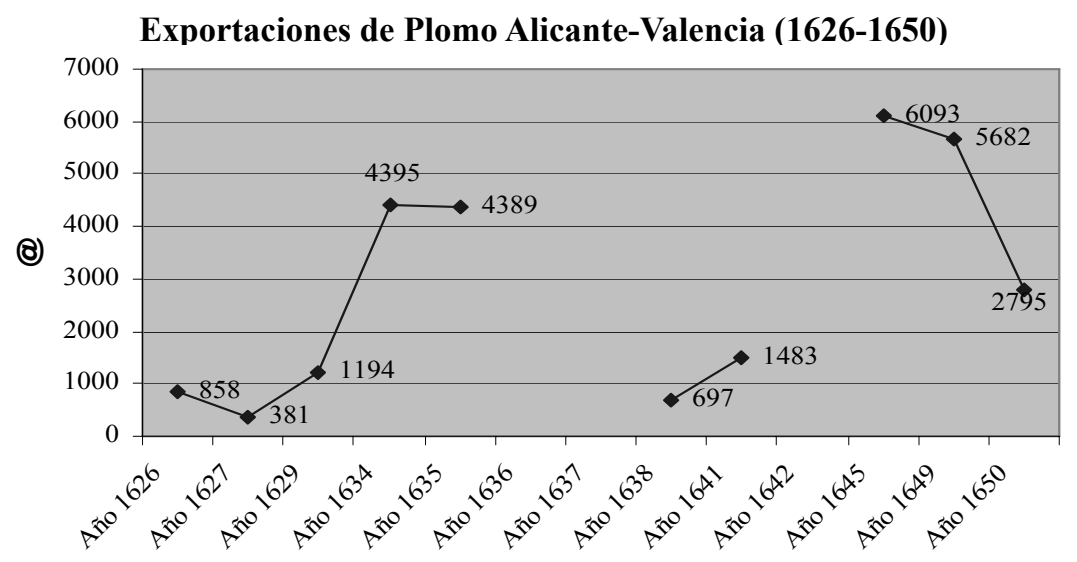

Los resultados obtenidos son lo suficientemente elocuentes por sí solos, no obstante nos corresponde hacer algún comentario, al producirse oscilaciones significativas entre años que no se registra ninguna embarcación alicantina transportando dicho metal (1636, 1637 y 1642) hasta el año 1645 donde se anota la mayor magnitud global exportada con6.093@. También resulta interesante la ascensión progresiva desde 1626 hasta 1635; la igualdad técnica (apenas $6 @$ de diferencia) en el binomio 1634-35 y el brusco desplome que se produce en los años siguientes. Así como la recuperación momentánea de 1638 y 1641 . Finalizando con el trienio $1645-1650$, se logra el 50\% de todas las expediciones a Valencia.

La nómina de las personas que hicieron posible este comercio la capitanea Antoni Baset que durante el mes de octubre de 1645 envió plomo a la pareja comercial formada por los aludidos Juan Cernesio y Escanio Sobregondi. Jaume Talagero se relacio-

38. Para saber más sobre estos mercaderes consultar la comunicación de BLANES ANDRÉS, R., «Mercaderes italianos en las importaciones marítimas valencianas en el segundo cuarto del Seiscientos (1626-1650)», Actas del 1r Coloquio Internacional sobre Los Extranjeros en la España Moderna, M. B. VILLAR GARCÍA y P. PeZzi Cristóbal (Eds.), Tomo I, Málaga, 2003, pp. 217-227. 
nará con Tomás Guelda durante el intervalo establecido por los meses de noviembre y diciembre de 1627-29 y 1634-35. Por último nos referiremos a Guillermo Trevill que centrará todas sus facturaciones en abril de 1645, siendo recepcionadas por Miquel Gil. Los perceptores valencianos más descollantes los podemos reducir a dos, Tomás Guelda que recibirá mineral a lo largo de todo el periodo estudiado a través de Juan Andrea, Jaume Talagero, Diego Escorsa, Jaime Miquel Andreu. Llacer Del Mar, que se encadenará con Melchor Mora y Melchior Miquel durante los dos primeros años y el último de nuestro trabajo.

Como se puede comprobar, tanto en las remisiones de acero como de plomo, surgen numerosas preguntas que necesitarían de un estudio más exhaustivo para poderlas contestar, análisis que sobrepasaría el objetivo que nos hemos marcado. No obstante las posibles respuestas las podemos encontrar en los acontecimientos bélicos que se están desarrollando en territorio catalano-rosellonés, siendo Valencia la proveedora no sólo de hombres y dinero, sino de almacén estratégico de donde guarnecer a las tropas de Felipe IV de todos los productos necesarios para una contienda.

Este apartado lo completaremos con los productos transformados que llegaron regularmente a la ciudad del Turia, como agujas de cabeza, quincallería, crisoles, cucharas, eslabones, espalmadores, alambre (de hierro, de púas o en barra), clavos, latón, hojalata, paellas, llaves, círculos, candelabros de estaño, campanas y azufre y salitre (componentes básicos en la elaboración de la pólvora). Las armas guardan una estrecha relación con los metales $\mathrm{y}$, al igual que ellos, sufrieron crisis exportadoras según el periodo. No obstante hemos podido contabilizar armas blancas (astas de lanzas, pomos de espadas, puñales, espadas y hojas de espada y picas), de fuego (arcabuces, cañones de escopeta sin montar, mosquetes y pistolas) y 208 barriles de pólvora (remitida por el Gobernador de Alicante al virrey de Valencia el 30 de septiembre de 1642).

Las mercaderías catalogadas dentro de las actividades intelectuales y artísticas forman capítulos de enorme interés. La literatura se halla representada por envíos de libros (manuscritos e impresos), sin especificarse su naturaleza, aunque podemos especular que algunos serían de tipo religioso; al ser remitidos de una orden monástica a otra, el prior (o priora) de esta, o a un fraile o monja concreto. La nómina la podemos completar con importantes cantidades de papel (blanco, de Francia, del Piamonte, de escribir, de estraza, de marca major y de marca major moreno). Las obras de arte están presente por medio de cuadros (en ningún caso se especifica la temática pictórica), retablos, gargantillas y pendientes. Cerraremos este apartado con artículos de tipo religioso como rosarios, estampas y medallas.

Bajo la denominación de «drogas y afines» hemos englobado diferentes productos; uno de los problemas que nos ha suscitado es la clasificación de las diferentes mercaderías que nos han ido suministrando los manuscritos. Las dificultades son consecuencia de la diversa utilización de algunas de ellas, ya que no sólo eran usadas en la farmacopea de la época, sino que en ocasiones servían como aditivo a un dulce, se utilizaba en la confitura, en la industria textil como materia tintorera, en la elaboración de perfumes, etc. Aunque hemos tratado de agruparlas por su aplicación más usual, somos conscientes de lo difícil de su ubicación. 
La barrilla fue una de las mercancías fundamentales del comercio exportador alicantino durante el siglo $X V I I I^{39}$, aunque el volumen expedido a Valencia, durante el segundo cuarto del Seiscientos, fue muy pobre y poco significativo en el montante global de las importaciones valencianas. Este producto químico estará acompañado del alcanfor, aguarrás y barniz.

El grupo medicamentoso agrupa una amplia lista de artículos como: matafaluga, comino, coloquínta, solimán trementina, tártaro, mirabolano, oropimente, sen o arsénico. Las materias tintóreas también tienen su representación por medios del almagre, azulete, palo brasil, gala fina y fustete

Los demás productos presentan un carácter esporádico, el tabaco, la cerámica, espejos, goma arábiga, incienso en polvo, plumas para escribir, yesca, jabón, piedras de sastre para marcar o cera.

Daremos por concluido este capítulo con las mercaderías de origen foráneo, que reexporta Alicante con destino a Valencia, la procedencia de estos géneros no deja lugar dudas, al incluirse junto al nombre del producto el lugar de donde se ha expedido. Así, podemos evidenciar que vienen pipas de Venecia; papel del Piamonte y de Francia; taburetes y sillas de Moscovia, mesas de Flandes, hojas de espada de Milán, dátiles de Berbería; cristales de Venecia, tabaco de Brasil; palo brasil de Santa Marta; alguno de estos artículos se registran de forma ocasional.

Somos conscientes que en este artículo no hemos podido abarcar toda la información que aporta la documentación investigada, obligándonos a restringir el análisis a unos aspectos determinados, que nos han introducido en lo que debieron ser las relaciones exportadoras entre Alicante y Valencia en el periodo comprendido entre 16261650. Lazos comerciales fluidos, donde la dársena alicantina juega el papel de gran almacén portuario, establecimiento donde recibe y distribuye géneros de muy diversa índole, por medio de un nutrido colectivo de dinámicos mercaderes que se interesarán, en ocasiones, por tramitar y vender artículos heterogéneos, así hemos podido comprobar que un mismo personaje se compromete en la facturación de pescado, de trigo o de otros productos de naturaleza diferente. Un universo en continua efervescencia; sólo adormecido ante los acontecimientos bélicos del momento, que asfixiaron transitoriamente las relaciones entre dos ciudades hermanadas por un mar, el Mediterráneo, embajador entre Alicante y Valencia.

39. GiMÉnEZ LóPEZ, E., Alicante en el siglo XVIII..., p. 384. 